effects of Phase 1 deprivation level may have disappeared even if rewarded trials had continued. Comparison of the results of previous investigations indicates, however, that the effects of previous deprivation level on performance in a test phase when deprivation level is equated at low are relatively small and transitory if extinction is employed as a test phase (Barry, 1958; Campbell \& Kraeling, 1954; Lewis \& Cotton, 1957) but are relatively large and persistent if a rewarded test phase is employed (O'Kelly \& Heyer, 1948; Timberlake, 1967; Zaretsky, 1966). It is possible, then, that the effects of previous deprivation level will persist in a test phase under low deprivation if reward is given, whether or not the reward is a new one, but will disappear quickly if extinction is given. On the other hand, if extinction is viewed as a large change in reward magnitude, it is possible that the effects of previous deprivation level will persist in a test phase under low deprivation if reward is unchanged or changed by a small amount, but not if reward magnitude is changed by a large amount. This latter view would imply that the effects of Phase 1 deprivation level would have been smaller in the present investigation when reward magnitude was changed rather than unchanged if a larger shift in reward magnitude had been employed.

The variations employed in the present investigation seem relevant to another issue as well. Typically, in the runway no positive contrast effect is obtained (e.g., Schrier, 1967). That is, a group shifted from small to large reward does not usually run faster than a group which receives large reward throughout training. It has been suggested that the lack of a positive contrast effect may possibly be attributed to a ceiling effect (Bower, 1961). This view implies that if the large-reward control group is performing at a submaximum level, a positive contrast effect would be obtained. In the present investigation, Group L-low was performing below maximum level in Phase 2, as evidenced by its slow speed relative to Group L-high in Phase 2, and Group L-high was also performing below maximum level in Phase 2 , as this group ran more slowly in Phase 2 than it had in Phase 1. Yet no positive contrast effects were obtained in the present investigation. Thus, the present results favor views which suggest that a positive contrast effect should not occur (e.g., Amsel, 1962 Capaldi \& Lynch, 1967) and do not support the ceiling effect hypothesis. Shanab \& Ferrell (1970) employed groups analogous to the present Groups S-high and L-high and obtained a positive contrast effect However, Shanab and Ferrell employed a modified Lashley Type III maze rather than a straight alley. The difference between Shanab and Ferrell's results and the present results is probably attributable to this difference in procedure.

\section{REFERENCES}

AMSEL, A. Frustrative nonreward in partial reinforcement and discrimination learning: Some recent history and a theoretical extension. Psychological Review, 1962, 69, 306-323.

BARRY, H. Effects of strength of drive on learning and on extinction. Journal of Experimental Psychology, 1958, 55, 473-481.

BOLLES, R. C. Theory of motivation. New Yowk: Harper \& Row, 1967.

BOWER, G. H. A contrast effect in differential conditioning. Journal of Experimental Psychology, 1961, 62, 196-199.

CAMPBELL, B. A., \& KRAELING, D. Response strength as a function of drive level during training and extinction. Journal of Comparative \& Physiological Psychology, 1954, 47, 101-103.

CAPALDI, E. D. Effect of an initial reward magnitude on subsequent resistance to extinction. Journal of Experimental Psychology, 1970, 86, 283-287.
APALD1, E. J., \& LYNCH, D. Repeated shifts in reward magnitude: Evidence in favor of an associational and absolute (noncontextual) interpretation. Joumal of Experimental Psychology, 1967, 75. 226-235.

GRAGG, L., BLACK, R. W. Runway performance following shifts in drive and reward magnitude. Psychonomic Science, $1967,8,177-178$.

LEWIS, D. J., \& COTTON, J. W. Leaming and performance as a function of drive level during acquisition and extinction. Journal of Comparative \& Physiological Psychology, 1957, 50, 189-194.

O'KELLY, L. I. \& HEYER, A. W. Studies in response motivation and retention: $I$. Retention of a simple habit. Journal of Comparative \& Physiological Psychology, $1948,41,466-478$

SHANAB, M. E., \& FERRELL, H. J. Positive contrast obtained in the Lashley maze under different drive conditions. Psychonomic Science, 1970, 20, 31-32.

SCHRIER, A. M. Effects of an upward shift in amount of reinforcer on runway performance of rats. Journal of Comparative \& Physiological Psychology, $1967,64,490-492$.

TIMBERLAKE, W. Straight alley acquisition drive and ad lib test performance. Psychonomic Science, $1967,9,585-586$.

ZARETSKY, H. H. Learning and performance in the runway as a function of the shift in drive and incentive. Journal of Comparative \& Physiological Psychology, 1966, 62, 218-222.

\title{
Extraacquisitional factors in extinction: The effect of feeding activities of neighboring rats*
}

\author{
PAUL T. P. WONG and KENNETH L. TRAUPMANN† \\ University of Texas at Austin, Austin, Tex. 78712
}

Following asymptotic extinction training, additional nonrewarded trials produced an increase in running speed. The rate of this response increment was negatively related to the time elapsed since neighboring rats had been fed. Further, the increment was obtained only in the start and run segments of the alley and not in the goalbox.

While it has been firmly established that a number of acquisitional variables, such as the magnitude or schedule of reward, affect extinction

*The research was supported by NSF Grant GB-14990X awareded to Abram Amsel.

+Requests for reprints should be addressed to Paul T. P. Wong, Department of Psychology, University of Texas at Austin, Tex. 78712 performance, the effect of extraacquisitional variables on extinction has received little attention. These extraacquisitional variables may be either historical or concurrent. Examples of historical extraacquisitional variables that might be relevant are early experiences such as handling, feeding frustration during the preweaning period, or any "incidental" learning prior to 
acquisition and extinction training. One example of a possibly relevant concurrent variable operating during extinction training relates to the feeding activities of rats in a colony. We have often observed that rats deprived of food for some time (say, 3 or 4 weeks) tend to display highly agitated behaviors, such as scratching and biting the wire-mesh walls of their cages, while neighboring rats are being fed. It seems highly probable that these agitated behaviors are indicative of a heightened general level of drive or arousal, which might have some effect on extinction performance. The present experiment was conducted to see if postasymptotic extinction performance could be influenced by varying the time elapsed since neighboring rats in a colony had been fed.

\section{METHOD}

The Ss were nine male albino rats from Holtzman Farms, Madison, Wisconsin. They were 90 days old upon arrival and were housed in individual cages with water always available. A daily deprivation regimen of $12 \mathrm{~g}$ of Wayne lab chow was maintained throughout the experiment.

The apparatus was a wooden runway which had an 11-in. entrybox, 11-in. startbox, and 39-in. alley. All segments of the runway were $3^{3 / 4}$ in. high and $2 \cdot 7 / 8$ in. wide and were covered with a transparent Plexiglas lid. Aluminum guillotine doors separated the entry and start sections and formed a 13 -in. goal compartment. The startdoor was of transparent Plexiglas. Three 1-ft running time measures, start, run, and goal, were taken by means of photoelectric circuitry.

Acquisition training consisted of 32 rewarded trials, 2 trials per day. Reward was in the form of one 300-mg Noyes pellet. During extinction, Ss were run at two trials per day until performance reached a stable asymptotic level (i.e., for the first 12 days); they were then run at one trial per day for the remainder of the experiment. During both acquisition and the first 12 days of extinction, the intertrial interval was approximately $30 \mathrm{~min}$. Postasymptotic extinction performance on Days 13 and 14 was treated as pretreatment baseline. Treatment began on Day 15 of extinction training and was continued for 36 days. It consisted of feeding the 20 rats housed in a neighboring rack, which was about $2 \mathrm{ft}$ away and directly facing the rack that housed the experimental Ss. On each day, Ss were run either $1 \mathrm{~min}$ or $1 \mathrm{~h}$ after the rats in the neighboring rack were fed. When the Ss were run on a particular day was determined randomly, with the restriction that the two types of trials each occur $50 \%$ of the time and that neither occur more than three times in a row. During the pretreatment period, neighboring rats were fed after all $S s$ had received their daily experimental training.

\section{RESULTS AND DISCUSSION}

Extinction data, including the pretreatment baseline performance and running speeds under the two treatment conditions, are presented in Fig. 1. Analyses of variance were performed on these data.

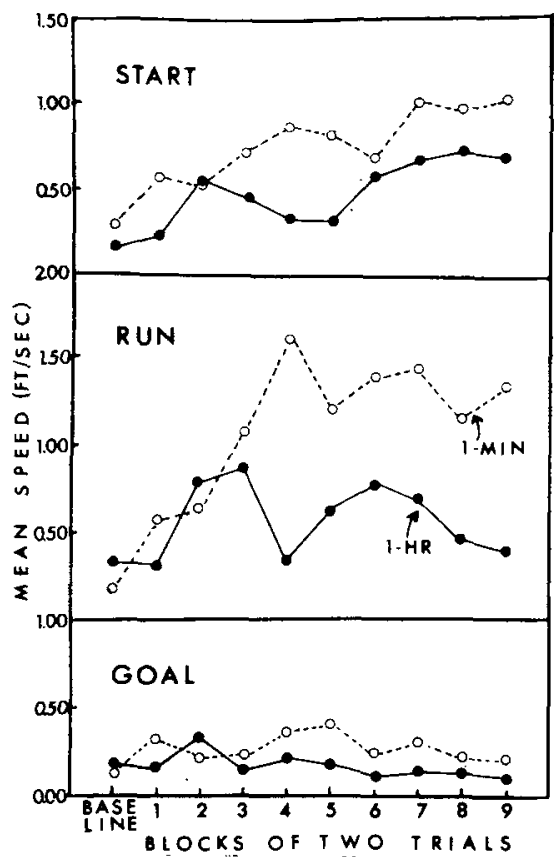

Fig. 1. Mean running speeds under two types of trial conditions.

The graph clearly shows that rats ran faster on 1-min trials in all segments of the alley, Fs $(1,304)=147.40,112.80$, and 18.56, all ps $<.01$. It was most interesting that the superiority of performance on 1-min trials increased with training, as supported by significant Treatment by Trials interactions, $F_{s}(18,304)=3.33,5.40$, and 1.90 , all ps $<.01$. This diverging function suggests that as conditioned anticipatory frustration (Amsel, 1967) is gradually extinguished with extended extinction training, runway performance becomes increasingly susceptible to such concurrent extraacquisitional variables as feeding activities of colony rats. This factor is particularly relevant in that it may have the potential of either masking out or enhancing the effects of differential acquisitional treatments; thus, control over concurrent feeding activities of colony rats is strongly indicated.

Another interesting finding is that the postasymptotic extinction training produced a successively increasing level of responding in the start and run segments, $\operatorname{Fs}(18,304)=11.30,5.70$, ps $<.01$, but not in the goal segment. This result is similar to that obtained during nonrewarded training preceding rewarded acquisition training (Wong, in press; Wong \& Traupmann, 1971). In both cases, the rats tended to retrace just before the goalbox, suggesting that being confined in an empty goalbox is an aversive event in itself. Further, the rate at which response strength increases during nonrewarded training has been found to be directly related to drive level (Wong \& Traupmann, 1971). Paul (1969) has also observed that during both nonrewarded acquisition and extinction training, rats displayed a high level of running; in fact, with very extended nonrewarded training ( 300 trials), the running speed was just as fast as the asymptotic food-rewarded running performance. Paul described the high level of nonrewarded running as "playful," characterized by bounding, hopping, circling, and bolting down the alley. In short nonrewarded running may be regarded as a nongoal-oriented locomotive activity, which is "intrinsically" motivated (Koch, 1956). In the case of initial nonrewarded training, the gradual increment probably reflects the extinction of fear evoked by the novel runway situation; in the case of postasymptotic extinction, the increasing response level suggests extinction of some conditioned inhibitory mechanism, such as anticipatory frustration.
REFERENCES

AMSEL, A. Partial reinforcement effects of vigor and persistence: Advances in frustration theory derived from a variety of within-subjects experiments. In $\mathrm{K}$. W. Spence and J. T. Spence (Eds.), The psychology of learning and motivation. Vol. 1 (Advances in research and theory). New York: Academic Press, 1967.

КОСН, S. Behavior as "intrinsically" regulated: Work notes towards a pre-theory of phenomena called "motivational," In M. R. Jones (Ed.), Nebraska symposium on motivation. Loncoln: University of Nebraska Press, 1956.

PAUL, L. High performance obtained with no reward. Psychonomic Science, 1969 , $14,24-26$.

WONG, P. T. P. Coerced approach, punishment of competing responses, and resistance to extinction in the rat. Journal of Comparative \& Physiological Psychology, in press.

WONG, P. T. P.. \& TRAUPMANN, K. L. Acquisition and extinction in satiated rats following chronic and severe food-deprivation. Paper read at the Southwestern Psychological Convention, 1971. 